\title{
Depresion Post Parto: Prevalencia de Test de Rastreo Positivo en Puerperas. Tacna 2009
}

\section{Postpartum Depression: Prevalence of Positive Puerperas in Tracking Tests. Tacna 2009}

${ }^{1}$ Gema Sologuren Garcia, ${ }^{2}$ Carmen Linares Torres, ${ }^{3}$ Paul E. Vega Adrianzen

\begin{abstract}
RESUMEN:
El objetivo de la presente investigación es determinar la prevalencia del test positivo para la depresión postparto según la Escala de Depresión Postnatal de Edimburgo, en puérperas atendidas en el Hospital Hipólito Unánue de Tacna (Consultorio de Obstetricia. Consultorio de Crecimiento y Desarrollo, Vacunación. Consultorio de Pediatría). Se trata de un estudio descriptivo transversal cuya muestra está formada por 480 puérperas. Los resultados indican que la prevalencia de la depresión post parto es de $37.5 \%$ en las puérperas sujeto de estudio durante el periodo de julio a diciembre del 2009. Asimismo, debemos referir que la presente investigación responde a las puntuaciones de la Escala de Edimburgo y no reemplaza al juicio clínico, considerando sus resultados como un signo de alerta que permitirá reconocer a las puérperas que necesitan ser derivadas para valoración especializada.
\end{abstract}

Palabras clave: depresión post parto, escala de depresión postnatal de Edimburgo

\section{ABSTRACT:}

The aim of this research is to determine the prevalence of positive test for postpartum depression according to the Edinburgh Postnatal Depression Scale in postpartum women treated at Hipólito Unámue Hospital in Tacna (Clinic of Obstetrics, Growlh and Development Clinic, Immunization, Clinic of Pediatrics). This is a descriptive transversal study whose sample consisted of 480 postpartum women who were attended. The results indicate that the prevalence of postpartum depression is $37.5 \%$ in the group subject of study cluring the period July to December 2009. We must also refer that this research responds to scores of Edinburgh scale and does not replace the clinical trial, considering their results as a warning sign that will recognize postpartum women who need to be referred for specialist assessment.

Keywords: postpartum depression, scale of natal depression of Edinburgh

\footnotetext{
'Magister en Docencia Universitaria .Licenciada en Obstetricia. Facultad de Ciencias de la Salud. Universidad Nacional Jorge Basadre Grohmann 2 Magister en Docencia Universitaria ,Licenciada en Obstetricia. Facultad de Ciencias de la Salud. Universidad Nacional Jorge Basadre Grohmann "Medico Psiquiatra. Facultad de Ciencias de la Salud Universidad Nacional Jorge Basadre (jrohmann
} 


\section{INTRODUCCIÓN}

La depresión en el post parto puede ser considerada como una respuesta psicológica y física compleja a las demandas de la vida diaria, sin embargo en muchas culturas se le da poca atención, siendo esta una patología muy frecuente $\mathrm{e}$ infradiagnosticada por to que el objetivo de la presente investigación fue determinar su prevalencia en las puérperas atendidas en el hospital Hipólito Unánue de Tacna, haciendo uso del Test positivo para depresión post parto según la Escala de Depresión Pos natal de Edimburgo, este es un test muy útil, muy sencillo y eficaz.

Conocer la prevalencia de la depresión post parto en la región Tacna tiene ventajas evidentes puesto que se beneficiaria de forma directa a la propia paciente y a su recién nacido.

\section{MATERIALY MÉTODOS}

El presente, es un estudio descriptivo transversal.

La muestra está formada por 480 puérperas que acudieron, durante los meses de Julio a Diciembre 2009. al Hospital de Apoyo Hipólito Unánue de Tacna (Consultorio de Obstetricia, Consultorio de Crecimiento y Desarrollo, Vacunación, Consultorio de Pediatría)

Los criterios de inclusión son:

Mujeres puérperas entre una semana y 6 meses,

Mujeres puérperas con nacidos vivos,

Mujeres cuyos hijos estén en el Programa Ampliado de Inmunizaciones (PAI) y en el Programa de Crecimiento y Desarrollo(CRED).

Madres que hablen español y

Madres que den el consentimiento informado verbal.

Los criterios de exclusión son:

Personas analfabetas,

Personas que no hablen el español y

Personas en duelo, en los últimos tres meses.

\section{Técnicas y Métodos de Trabajo}

Para deterninar el riesgo de depresión postparto se utilizó la Escala de Depresión Post Natal de Edimburgo (EPDS)

\section{El instrumento es de auto-registro.}

Para determinar la prevalencia de la depresión post parto se consideró lo siguiente:

\section{Prevalencia puntual:}

La prevalencia puntual es la frecuencia de una enfermedad o condición en un punto del tiempo. Es una proporción que expresa la probabilidad de que una persona sea un caso en un momento o edad determinados.

Es la medida estimada en las Ilamadas encuestas de prevalencia o Transversales.

La prevalencia puntual se estima con la siguiente fórmula:

$$
\text { Prevalencia puntual }=\mathrm{Ct} / \mathrm{Nt}
$$

$\mathrm{Ct}=$ número de casos existentes (prevalentes) en un momento o edad determinados.

$\mathrm{Nt}=$ número total de individuos en la población en ese momento o edad determinados.

\section{RESULTADOS Y DISCUSIÓN}

En la presente investigación se demuestra que la prevalencia de depresión post parto en las puérperas encuestadas en el Hospital de Apoyo Hipólito Unanue de Tacna es de es de $37.5 \%$ de acuerdo a la escala de Edimburgo - Test de rastreo positivo. Esta cifra comparada con otras en investigaciones tales como la de Gladys Eugenia Canaval realizada en Colombia en el año 2000, son menores ya que esta investigadora encontró un $57 \%$ de mujeres con sintomatología depresiva en el periodo post parto.

Por otro lado, en una investigación realizada en el Hospital universitario de Brasilea por Alberto Moreno Zaconeta y colaboradores concluyeron que es dificil determinar la prevalencia real de la depresión post parto porque los estudios difieren demasiado en lo que se refiere en metodología y poblaciones analizada, pero puede aceptarse que 10 a $20 \%$ de las mujeres que dan a luz son afectadas por esta entidad.

A nivel nacional Pilar Aramburú en Junio 2004 concluyo en su investigación realizada en Lima Metropolitana sobre Prevalencia y factores asociados a depresión post parto en mujeres atendidas en establecimientos de salud de primer nivel que la tasa de prevalencia es de $24 \%$.

Asimismo, debemos referir que la presente investigación responde a las puntuaciones de la Escala de Edimburgo y no reemplaza al juicio clínico, considerando sus resultados como un signo de alerta que permitirá reconocer a las puérperas que necesitan ser derivadas para valoración especializada

\section{CONCLUSIONES}

La prevalencia de la depresión post parto según el Test de rastreo positivo (Escala de Edimburgo) es de 37.5\% en las puérperas sujeto de estudio durante el periodo de julio a diciembre del 2009. Asimismo, debemos referir que la presente investigación responde a las puntuaciones de la Escala de Edimburgo y no reemplaza al juicio clinico, considerando sus resultados como un signo de alerta que permitirá reconocer a las puérperas que necesitan ser derivadas para valoración especializada.

El $45.8 \%$ de las puérperas encuestadas responden frente a la pregunta: He podido reir y ver el lado bueno de las cosas que "no tanto ahora", y el $33 \%$ "tanto como 
siempre"y solo el $2.08 \%$ responde "no no he podido".

La mitad de las puérperas refiere que ha mirado el futuro con placer "álgo menos de lo que solía hacer"; seguido de $31.3 \%$ "tanto como siempre" y solo un $2.08 \%$ responde "no nada".

Frente a la pregunta: Me he culpado sin necesidad cuando las cosas marchaban mal, el $47.9 \%$ responde que "no muy a menudo", seguido de "si algunas veces" conel $43.8 \%$.

El $54.2 \%$ de puérperas responde que "sí, a veces" ha estado ansiosa y preocupada sin motivo, el $35.4 \%$ "casi nada", y ninguna responde "sí, a menudo".

La mitad de las puérperas encuestadas manifiestan haber sentido miedo o pánico sin motivo alguno "sí, a veces", seguido de un $33.3 \%$ que refiere que "No, no mucho"; y un $6.3 \%$ "sí, bastante". El $43.8 \%$ de puérperas responden que "si a veces" las cosas las oprimen o agobian, el $33.3 \%$ refieren que "no, casi nunca", frente al $6.3 \%$ que dicen "si, casi siempre".

El $33.3 \%$ de las puérperas encuestadas responden que "si, a menudo" se han sentido tan infelices que han tenido dificultad para dormir, siendo el mismo porcentaje para las que responden "que no muy a menudo"; el $14.6 \%$ responde que "si casi siempre" y un $18.8 \%$ "no, nada".

El $39.6 \%$ de las puérperas encuestadas "no, muy a menudo" se han sentido tristes y desgraciadas, el $25 \%$ "sí, bastante a menudo" y el $20.8 \%$ "no, nada", frente al $14.6 \%$ que dicen "si casi siempre".

E1 43.8\% responde que "solo ocasionalmente" ha estado tan infeliz que ha estado llorando, seguido de un $22.9 \%$ "si, bastante a menudo"; el $18.8 \%$ "sí, casi siempre", frente a un $14.5 \%$ que dicen "no nunca".

Se evidencia que el $45.8 \%$ de las puérperas encuestadas manifiestan que "no, nunca", han pensado en hacerse daño a si mismas, y el $25 \%$ han pensado en hacerse daño asimismas.

\section{REFERENCIAS BIBLIOGRÁFICAS}

Barra F., Barra L. Solis J. Depresión Post Parto. Hacia un tratamiento integral. Actualizaciones en Psicoterapia Integrativa [Publicación periódica en linea en Instituto Chileno de Psicoterapia Integrativa]. Vol. I, 77-88 (2009). Citado en Octubre del 2009.

Cox J. L., Holden J. M., Sagovsky R. Escala de Depresión de Post-Parto de Edinburgh. Revista Británica de Psiquiatria, Junio de 1987, Volumen 150.

Manchado Ramírez F, Garcia Serrano T, Moya Rüegg N, Bernabéu Sáez N, Cerdá Díaz R. Depresión puerperal. Factores relacionados. Aten Primaria 1997; 20(4): 161-66.

Postpartum Disorders. The Harvard Medical School Mental Health Letter May 1989.

Ríos Rial B, Garcia-Noblejas Sánchez- Migallón J, Sánchez Cubas S. DepresiónPostparto. En: Trastornos depresivos en la mujer (Depresión en patologías orgánicas). Ed. Edicomplet, S.A. Madrid 1999. 12-26.

Sebastián Romero E, Mas Lodo N, Martín Blázquez M, Raja Casillas MI, Izquierdo Zainarriego MJ, Vallés FernándezN, Metola Gómez M. Depresión Postparto en el Área de Salud de Toledo. Aten Primaria 1999: 24(4): 215-219.

\section{Correspondencia:}

Gema Sologuren Garcia

Ciudad Universitaria Fundo "Los Granados"

Av. Miraflores s/n. Tacna. Perú.

Urb. SantaAna A-22. Tacna. Perú

gemasologuren5@unjbg.edu.pe 